\title{
Development of a quantitative real-time RT-PCR for kinetic analysis of immediate-early transcripts of Rat cytomegalovirus
}

\author{
H.S. LOH' ${ }^{1}$ M.L. MOHD-AZMI ${ }^{2}$
}

${ }^{1}$ School of Biosciences, Faculty of Science, The University of Nottingham Malaysia Campus, Jalan Broga 43500 Semenyih, Selangor

Darul Ehsan, Malaysia; ${ }^{2}$ Institute of Bioscience, University Putra Malaysia 43400 UPM Serdang, Selangor Darul Ehsan, Malaysia

Received January 1, 2009; accepted October 13, 2009

\begin{abstract}
Summary. - One-step real-time RT-PCR assay was developed for quantification of the immediate-early (IE), namely IE1 and IE2 transcripts of Rat cytomegalovirus (RCMV), strain ALL-03 in rat embryonic fibroblast cells (REF). This in-house SYBR ${ }^{\circledR}$ Green I based RT-PCR was shown to have higher amplification efficiency and detection limit as compared to a commercially available real-time RT-PCR kit in quantifying these two transcripts. The quantification histogram revealed the divergence of transcription activities of the two IE genes. The IE1 transcript had a concentration peak at $7 \mathrm{hrs}$ post infection (p.i.), whereas IE2 transcript at $20 \mathrm{hrs}$ p.i. Regulation of IE expression is critical for determination, whether the infection is going to be abortive, lytic or latent. Therefore, this in-house developed quantitative RT-PCR assay offers an alternative for diagnosis and monitoring of the acute cytomegalovirus (CMV) infection directed at IE transcript detection.
\end{abstract}

Keywords: Rat cytomegalovirus; immediate-early; real-time RT-PCR; SYBR ${ }^{\circledR}$ Green I

\section{Introduction}

CMVs are widespread species-specific viruses belonging to the family Herpesviridae, the subfamily Betaherpesvirinae that cause acute, persisting or latent infections in humans and animals. Infections with Human CMV (HCMV) are primarily asymptomatic in immunocompetent individuals, but can be life-threatening in immunocompromised individuals, such as AIDS patients and organ transplant recipients.

Expression of CMV genes is controlled by a cascade of transcriptional events leading to the synthesis of 3 categories of viral proteins designated as major immediate-early (MIE or $\alpha$ ), early ( $\mathrm{E}$ or $\beta)$, and late (L or $\gamma)$. The MIE genes are the

E-mail: Sandy.Loh@ nottingham.edu.my; fax: +603-89248018.

Abbreviations: $\mathrm{C}(\mathrm{T})=$ threshold cycle; $\mathrm{CMV}(\mathrm{s})=$ cytomegalovirus $(\mathrm{es})$; HCMV = Human CMV; HEL = human embryonic lung; IE = immediate-early; MCMV = Mouse CMV; MIE = major IE; NTC = no template control; p.i. = post infection; $q$ RT-PCR = quantitative real-time RT-PCR; QT system $=$ QuantiTect $^{\circledR}$ SYBR $^{\circledR}$ Green RTPCR; $\mathrm{R}^{2}=$ correlation coefficient $\mathrm{RCMV}=\mathrm{Rat} \mathrm{CMV} ; \mathrm{REF}=$ rat embryonic fibroblast; $\mathrm{Tm}=$ melting temperature; TthPlus system $=$ TthPlus $^{\mathrm{TM}}$ DNA polymerase assay first viral genes expressed during infection independently on de novo synthesis of the viral proteins (Mocarski, 1996). The MIE locus consists of an enhancer/promoter region that directs transcription of the region consisting of five exons. Differential splicing of the first three exons to either exon 4 or 5 generates three different transcripts, namely IE1, IE2, and IE2A (Beisser et al., 1998). The architecture of MIE regions of HCMV, RCMV and mouse CMV (MCMV) is similar. There are striking homologies in exon 5 of the IE2s of the HCMV and RCMV and the analogous ie3 of MCMV (Messerle et al., 1992).

In our previous studies, we detected a transplacental RCMV isolate (strain ALL-03) obtained from Rattus rattus diardii (Loh et al., 2003) that was able to cross the placenta and infect offsprings congenitally (Loh et al., 2006). Further, we were studying the HCMV infection and disease in utero and in neonatal model (Loh et al., 2006, 2007a). To fully exploit the RCMV-rat system, it was necessary to obtain a detailed picture of the molecular mechanisms involved in the replication of the virus. In this regard, we previously explored one of the most crucial regions of RCMV genome, i.e. the exon 4 and 5 of MIE region (Loh et al., 2007b).We employed PCR as one of the molecular detection systems 
for RCMV infection using primers flanking the exon 4. The RCMV infection was identified in many target organs and showed some pathological features of HCMV infection (Loh et al., 2006, 2007a).

For continual attempt to understand the molecular replication of RCMV in vitro, a quantitative real-time RT-PCR (qRT-PCR) assay by applying the SYBR ${ }^{\circledR}$ Green I was developed to study the transcription levels of IE mRNAs. This real-time analysis of kinetic RT-PCR enables a truly quantitative analysis of mRNA concentration and reduces a contamination along with an assay time, because usual post-PCR steps are no longer necessary. In addition, the $\mathrm{SYBR}^{\circledR}$ Green I assay can easily verify the non-specific amplification by melting temperature calculation through melting curve (Ririe et al., 1997). The conceptual simplicity, practical ease (Wall and Edwards, 2002) and promise of high throughput (Cohen et al., 2002) have made the qRT-PCR detection assay the most widely used RNA quantification method for various research applications including monitoring transcription in vitro (Liu et al., 2002).

In this paper, we report a development of the one-step real-time RT-PCR assay particularly for the quantification of kinetic levels of IE1 and IE2 transcripts in vitro. Furthermore, a sensitivity and efficiency of this assay was compared with those of a commercially available kit.

\section{Materials and Methods}

Virus and cells. RCMV strain ALL-03 was employed (Loh et $a l ., 2003)$. Rat embryonic fibroblast cells were used throughout the work.

Isolation of total RNA. Confluent monolayers of REF were infected with RCMV at multiplicity of infection (MOI) of 2. Mock- and RCMV-infected REF cells were trypsinized with antibiotic/trypsin/versene solution (ATV) containing $50 \mu \mathrm{g} / \mathrm{ml}$ cycloheximide at $2 \mathrm{hrs}$ intervals and subjected to a RNA extraction by using RNeasy ${ }^{\circledR}$ Mini (Qiagen). The extracted total RNA was treated with RNase-free DNase I (New England Biolabs) in order to remove contaminating genomic DNA before use.

Quantitative real-time RT-PCR optimizations. Different parameters were subjected to optimization to obtain a best possible protocol for the one-step real-time RT-PCR assay including the concentrations of primers, manganese acetate $\mathrm{Mn}(\mathrm{OAc})_{2}, \mathrm{SYBR}^{\circledast}$ Green I, RNA template, temperatures for primer annealing, RT and fluorescence data acquisition steps. One ng of each synthetic sense RNA oligonucleotides (IE1 sense RNA, Exon 4: nt 269-371; IE2 sense RNA, Exon 5: nt 302-406; Loh et al., 2007b) and 500 ng of extracted positive sense RNA were used as positive templates. The mixture in volume of $25 \mu$ contained $1 \mathrm{x}$ one-tube buffer, 2.5-5.0 $\mathrm{mmol} / \mathrm{l} \mathrm{Mn}(\mathrm{OAc}), 0.3 \mathrm{mmol} / \mathrm{l} \mathrm{dNTP}, 0.25-0.75 \mu \mathrm{mol} / \mathrm{l}$ of each forward primer (RT1-F: 5'-TGACTAACTGTCCATCGGTAAC-3'; RT2-F: 5'-TGCATACTCAGATGATGATGGAGATACG-3') and reverse primer (RT1-R: 5'-CGATCCTGCATCATGATCTTGA-3'; RT2-R 5'-ACCTGTAAGCGTGGGAGATCATAACGTA-3'), tem- plate RNA, 1.5 units of TthPlus ${ }^{\mathrm{TM}}$ DNA polymerase (GeneCraft) and nuclease-free water was prepared on ice. The reaction mixtures were incubated at $50-60^{\circ} \mathrm{C}$ for 30 mins followed by initial denaturation at $95^{\circ} \mathrm{C}$ for $10 \mathrm{mins}$ and subjected to 40 amplification cycles at $94^{\circ} \mathrm{C}$ for 15 secs, at $50-72^{\circ} \mathrm{C}$ for 15 secs and at $72^{\circ} \mathrm{C}$ for 20 secs. Final extension run at $72^{\circ} \mathrm{C}$ for 2 mins and finally, the amplified products were detected by electrophoresis.

For SYBR ${ }^{\circledR}$ Green I (Molecular Probes) optimization, a dilution series of SYBR Green concentration (1:1,000 to 1:100,000) were tested in 100 pg IE1 synthetic sense RNA oligonucleotide (positive control) and no template control (NTC; negative control) using primer set RT1-F and RT1-R according to the modified protocol.

In order to set the fluorescence acquisition temperature for real-time RT-PCR modified protocol, the melting temperature $(\mathrm{Tm})$ of primer-dimers was determined. Primer-dimers for both RT1 and RT2 were generated under reaction conditions such as low annealing temperature, long extension time, high primer concentration, very low initial template concentration. Primer-dimers were detected by melting curve analysis in conjunction with agarose gel electrophoresis. Besides, the sensitivity limit of TthPlus system (in-house developed assay using TthPlus ${ }^{\mathrm{TM}}$ DNA polymerase) was elucidated by applying different dilutions of RNA template.

One-step real-time RT-PCR. A 'one-tube/one-enzyme' realtime RT-PCR system (TthPlus) was developed for mRNA quantification assay using DNA Engine Opticon ${ }^{\mathrm{TM}} 2$ System (BioRad) and to compare relatively with QuantiTect ${ }^{\circledR} \mathrm{SYBR}^{\circledR}$ Green RT-PCR Kit (Qiagen). The $25 \mu \mathrm{l}$ mixture contained similar components as mentioned in section Quantitative real-time RT-PCR optimizations except for a ten-fold dilution series of each synthetic sense RNA oligonucleotides, i.e. either IE1 or IE2 (for standard curve and quantification) or $500 \mathrm{ng}$ of the extracted sample RNA, $1 \mu \mathrm{l}$ of $\mathrm{SYBR}^{\circledR}$ Green I $(1: 5,000)$ and $3.5 \mathrm{mmol} / \mathrm{l} \mathrm{Mn}(\mathrm{OAc})_{2}$ was prepared. RT step was conducted at $60^{\circ} \mathrm{C}$ for 30 mins followed by initial denaturation at $95^{\circ} \mathrm{C}$ for 10 mins. The 40 -cycle amplification and quantification conditions were stated as follows: denaturation at $94^{\circ} \mathrm{C}$ for 15 secs, annealing at $60^{\circ} \mathrm{C}$ (primer set RT1-F and RT1-R) or $68^{\circ} \mathrm{C}$ (primer set RT2-F and RT2-R) for 15 secs, extension at $72^{\circ} \mathrm{C}$ for 20 secs with a single fluorescence measurement at the end of the $72^{\circ} \mathrm{C}$ segment. A final extension was done at $72^{\circ} \mathrm{C}$ for 5 mins and followed by a melting curve analysis. All these parameters were chosen based on the best performance obtained from the optimization steps.

Some modifications were then applied to the conditions in order to improve the efficiency of absolute quantification. The modified cycling conditions in amplification and quantification steps were as follows: $95^{\circ} \mathrm{C}$ for 15 secs, $60^{\circ} \mathrm{C}$ or $68^{\circ} \mathrm{C}$ for 15 secs, $72^{\circ} \mathrm{C}$ for 20 secs and then followed by fluorescence acquisition step at $78^{\circ} \mathrm{C}$ (primer set RT1-F and RT1-R) or $79^{\circ} \mathrm{C}$ (primer set RT2-F and RT2-R).

Data were analyzed using OpticonMONITOR ${ }^{\mathrm{TM}}$ Analysis Software. Every real-time RT-PCR assay contained NTCs, test samples and a $\log _{10}$ dilution series $(0.001 \mathrm{pg}$ to $10 \mathrm{ng})$ of standard RNA control in triplicates for absolute quantification. A threshold of fluorescence 0.010 was fixed to standardize the $\mathrm{C}(\mathrm{T})$ value calculation and minimize the variations between each assay. The mean values were calculated in order to plot a quantification histogram expressing the kinetic levels of IE1 and IE2 mRNAs for each $2 \mathrm{hrs}$ interval in $\log _{10}$ concentrations of $\mathrm{pg}$ mRNA per $\mu \mathrm{g}$ of total cellular 
RNA. The trend of the kinetic transcription level of each mRNA was represented by a polynomial graph and created formulation. Commercial real-time RT-PCR kit. The QuantiTect ${ }^{\circledR} \mathrm{SYBR}^{\circledR}$ Green RT-PCR kit (Qiagen) referred to as QT system was employed for a relative comparison with TthPlus system. The manufacturer's instructions were followed with only one modification concerning the annealing temperature of the primers. A cocktail of $25 \mu \mathrm{l}$ reaction volume contained 1x QuantiTect ${ }^{\circledR} \mathrm{SYBR}^{\circledR}$ Green RT-PCR Master Mix, $0.5 \mu \mathrm{l}$ QuantiTect ${ }^{\circledR}$ RT Mix, $0.5 \mu \mathrm{mol} / \mathrm{l}$ of each forward primer (RT1-F or RT2-F), $0.75 \mu \mathrm{mol} / \mathrm{l}$ of each reverse primer (RT1-R or RT2-R), a ten-fold dilution series in a range of 0.01-100 pg of each synthetic sense RNA oligonucleotide (for standard curve) and RNase-free water were prepared. The reaction mixture was incubated at $50^{\circ} \mathrm{C}$ for 30 mins followed by the reverse transcriptases inactivation, activation of HotStarTaq DNA polymerase and initial denaturation of cDNA at $95^{\circ} \mathrm{C}$ for 15 mins. The mixture was subjected to 40 amplification cycles similar to the protocol of TthPlus system without the additional fluorescence acquisition step.

Comparison of TthPlus and QT systems. The modified protocol of TthPlus system was compared to the standard protocol of QT system. Ten-fold serial dilutions ranging from $0.001-100 \mathrm{pg}$ of sense RNA oligonucleotides (IE1 and IE2) were tested in triplicates and the mean $\mathrm{C}(\mathrm{T})$ values were plotted against the amount of initial RNA input to generate standard curves for genes IE1 and IE2 in order to compare their differences in the amplification efficiencies (slopes) and sensitivities ( $y$ intercepts). The amplification efficiency calculated as $\left[10^{(-1 / \text { slope })}-1\right] \times 100$ was expressed in $\%$. The smaller the $\mathrm{C}(\mathrm{T})$ value ( $y$ intercept) in the regression equation, the greater the sensitivity of the RT-PCR reaction.

\section{Results}

\section{Quantitative real time RT-PCR optimizations}

A partial fragment of each RCMV spliced transcripts, IE1 and IE2, was successfully amplified with the use of primer sets, RT1-F/RT1-R and RT2-F/RT2-R, respectively. The desired RT-PCR amplicons of $103 \mathrm{bp}$ and $105 \mathrm{bp}$ were respectively generated in IE1 and IE2 synthetic RNA oligonucleotides as well as in the positive RNA. A gradient of annealing temperature from $50^{\circ} \mathrm{C}$ to $62.9^{\circ} \mathrm{C}$ successfully generated a positive distinct band in the synthetic IE1 RNA oligonucleotide and positive RNA, while IE2 amplicon gave a distinct band in the range of $50^{\circ} \mathrm{C}$ to $71.5^{\circ} \mathrm{C}$. Since the intensities of the band generated at $62.9^{\circ} \mathrm{C}$ and $70.2-71.5^{\circ} \mathrm{C}$ for IE1 and IE2 genes, respectively, were fainter, the annealing temperatures chosen were $60^{\circ} \mathrm{C}$ for primer set RT1-F/RT1-R for the gene IE1 and $68^{\circ} \mathrm{C}$ for primer set RT2-F/RT2-R for the gene IE2 in both TthPlus and QT systems used.

When the unmodified protocol was used (i.e. without additional fluorescence acquisition after the extension step for both primer sets, RT1-F/RT1-R and RT2-F/RT2-R), primer-dimers were shown on serial dilutions of sense RNA oligonucleotides of IE1 and IE2 at low annealing temperature and with very low concentrations of start-

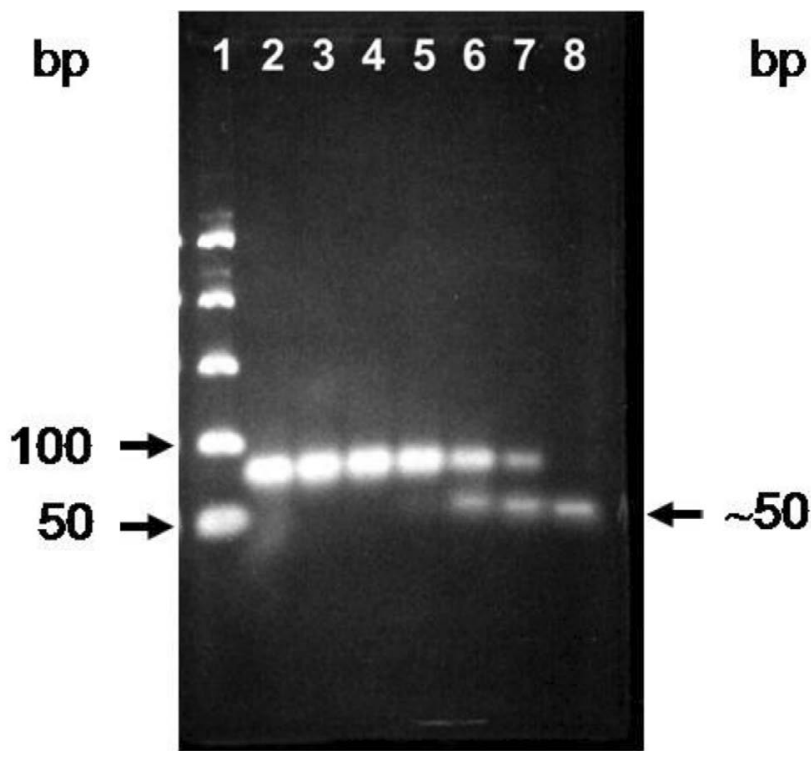

Fig. 1

RT-PCR assay using primer set RT1 with annealing temperature of $50^{\circ} \mathrm{C}$ with ten-fold serial dilutions of IE1 sense RNA oligonucleotide

Size markers (lane 1), 100 pg (lane 2), 10 pg (lane 3), 1 pg (lane 4), 0.1 pg (lane 5), $0.01 \mathrm{pg}$ (lane 6), $0.001 \mathrm{pg}$ (lane 7), NTC (lane 8).

ing RNA $(\leq 0.01 \mathrm{pg})$. However, there was an exception for diluted RNA template $(\geq 0.1 \mathrm{pg})$ that did not give any detectable primer-dimers, although the annealing temperature was set at $50^{\circ} \mathrm{C}$ (primer set RT1) and $60^{\circ} \mathrm{C}$ (primer set RT2). This result was best demonstrated by the electrophoresis of real-time RT-PCR products of IE1 mRNA in serial ten-fold dilutions (0.001-100 pg) that showed only specific IE1 amplicon (103 bp) without apparent primer-dimer (Fig. 1, lanes 2-5). Primer-dimer with a molecular size of $\sim 50 \mathrm{bp}$ was detected starting from $0.01 \mathrm{pg}$ mRNA and it was present also in NTC (Fig. 1, lanes 6-8). The melting curve analysis of the IE1 RT-PCR products in ten-fold dilution series from 0.1 to $0.001 \mathrm{pg}$ of IE1 RNA confirmed these results (Fig. 2). The primer-dimer was generated in ascending dilution of template RNA and the sharp melting peak at $0.1 \mathrm{pg}$ was split to two peaks at $0.01 \mathrm{pg}$ (Fig. 2, curves a, b). The two melting peaks observed with amounts of 0.01 and 0.001 pg indicated that the primer-dimer co-amplified with the desired IE1 product (Fig. 2, curves b, c). This result was confirmed by agarose gel electrophoresis (Fig. 1, lanes $6,7)$. The NTC sample containing the primer-dimer was the only source of fluorescence (Fig. 2, curve d), what corresponded to the band detected in agarose gel electrophoresis (Fig. 1, lane 8). On average, the primerdimers had a lower Tm than that IE1 product $\left(\leq 75.6^{\circ} \mathrm{C}\right.$ 


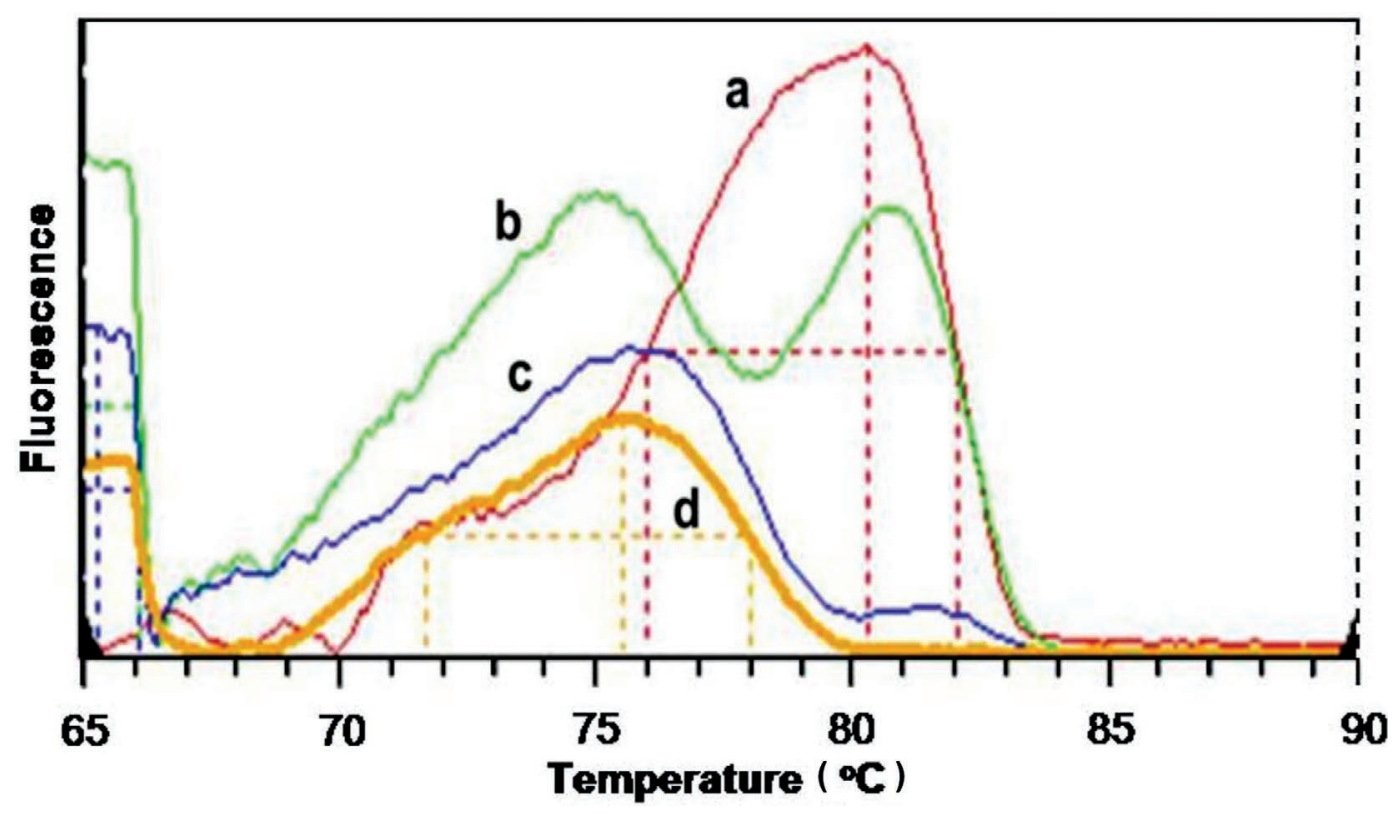

Fig. 2

Melting curve analysis of ten-fold serial dilutions of IE1 sense RNA oligonucleotide in TthPlus system $0.1 \mathrm{pg}$ (curve a), $0.01 \mathrm{pg}$ (curve b), $0.001 \mathrm{pg}$ (curve c), NTC (curve d).

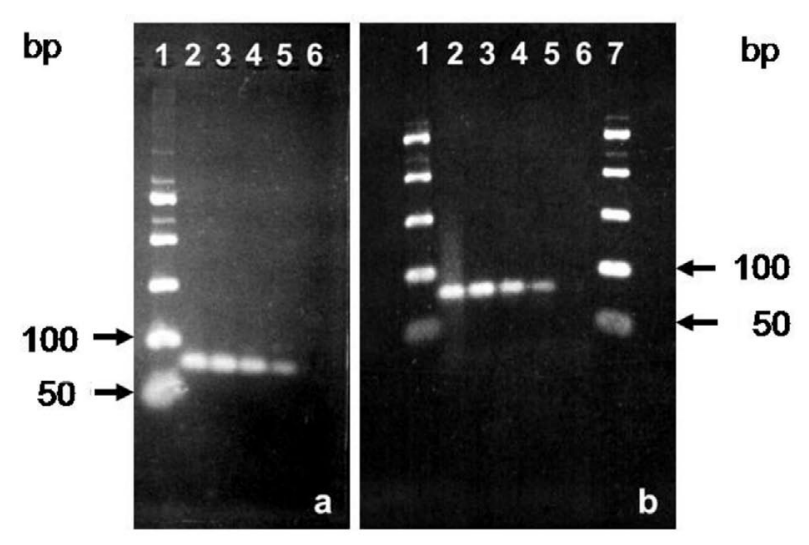

Fig. 3

Real-time RT-PCR with modified cycling conditions

(a) Amplification of IE1 sense RNA oligonucleotide using primer set RT1 with fluorescence acquisition segment of $78^{\circ} \mathrm{C}$. (b) Amplification of IE2 sense RNA oligonucleotide using primer set RT2 with fluorescence acquisition segment of $79^{\circ} \mathrm{C}$. Size markers (lanes 1, 7), 1 pg (lane 2), 0.1 pg (lane 3), $0.01 \mathrm{pg}$ (lane 4), $0.001 \mathrm{pg}$ (lane 5), NTC (lane 6).

vs $\left.81.0^{\circ} \mathrm{C}\right)$. Therefore, an extra fluorescence acquisition segment of $78^{\circ} \mathrm{C}$ was added into the modified protocol. On the other hand, $79^{\circ} \mathrm{C}$ was chosen for the fluorescence data reading segment for IE2 RNA oligonucleotide. There was a significant decrease in fluorescence of the positive
RNA controls as compared to the reactions not employing this strategy. Nevertheless, primer-dimers were not found in IE1 and IE2 RNA even with dilutions of 0.001 pg and NTC, when the procedure was conducted at annealing temperatures, $60^{\circ} \mathrm{C}$ and $68^{\circ} \mathrm{C}$ and the IE1 and IE2 sense oligonucleotides served as templates, respectively (Fig. 3a,b, lanes 5, 6).

\section{Comparison of TthPlus and QT systems}

The OpticonMONITOR ${ }^{\mathrm{TM}}$ analysis showed a linear relationship between the amount of input RNA and the $\mathrm{C}(\mathrm{T})$ values for IE1 and IE2 specific products, individually over six $\log _{10}$ dilutions for TthPlus system and five $\log _{10}$ dilutions for QT system. The mean $\mathrm{C}(\mathrm{T})$ values were plotted against amount of RNA input to generate mean standard curves (Fig. 4) producing correlation coefficient $\left(\mathrm{R}^{2}\right)$ values for the reaction in excess of 0.9994 (IE1 RNA) and 0.9975 (IE2 RNA) for TthPlus system and 0.9913 (IE1 RNA) and 0.9889 (IE2 RNA) for QT system. These mean $\mathrm{C}(\mathrm{T})$ values are depicted in Table 1 for comparison. The use of the modified protocol of TthPlus system produced lower $\mathrm{C}(\mathrm{T})$ values at all respective RNA inputs and therefore conferred higher sensitivity to the TthPlus system than to the QT system. In addition, the TthPlus system had a higher amplification efficiency for IE1 $(90.5 \%$ vs $82.25 \%)$ and comparable amplification efficiency for IE2 (103.26\% vs $102.00 \%$ ) in comparison with the QT system. 


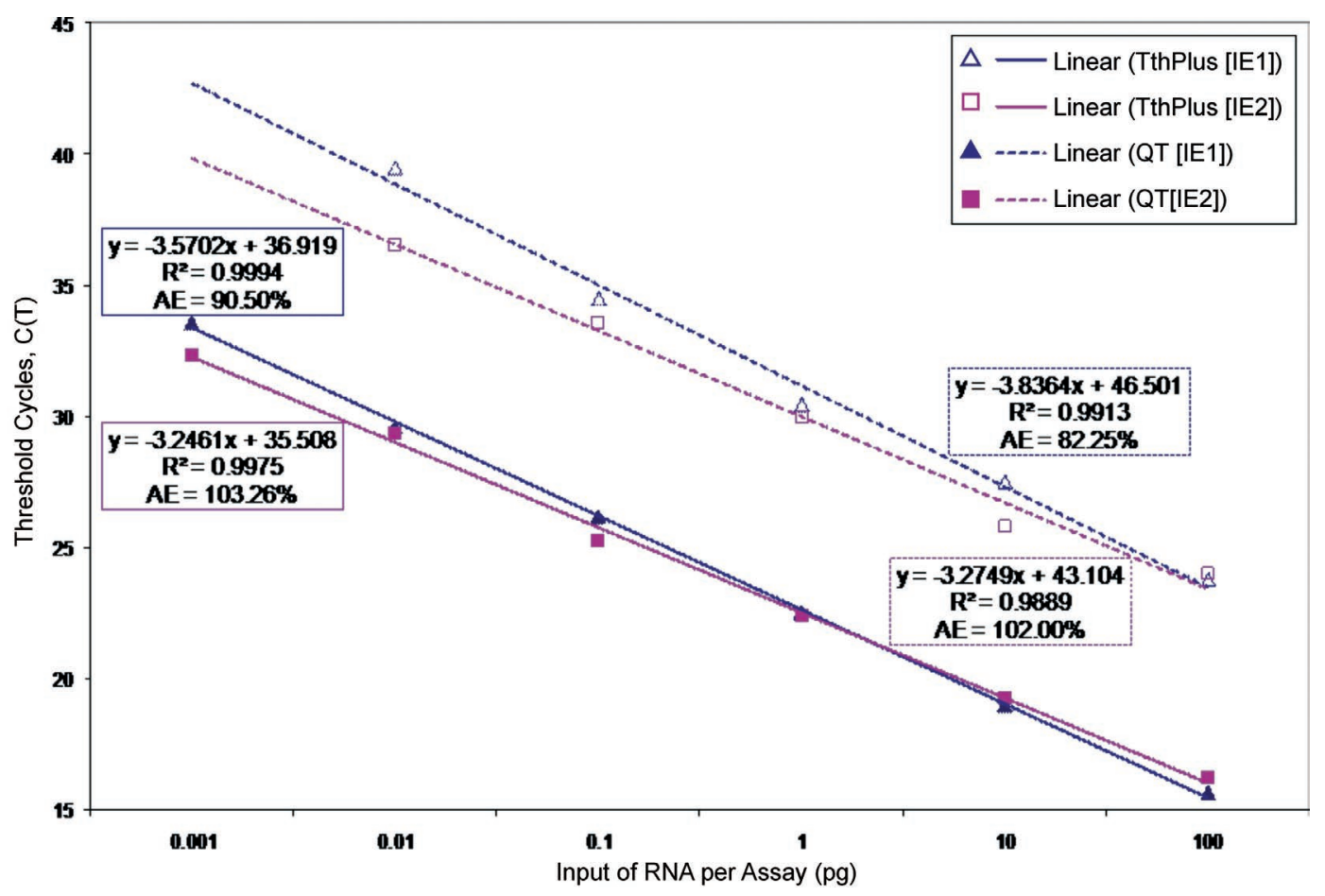

Fig. 4

Standard curves showing mean $\mathrm{C}(\mathrm{T})$ values in TthPlus and QT systems $\mathrm{R}^{2}=$ correlation coefficient, $\mathrm{AE}=$ amplification efficiency.

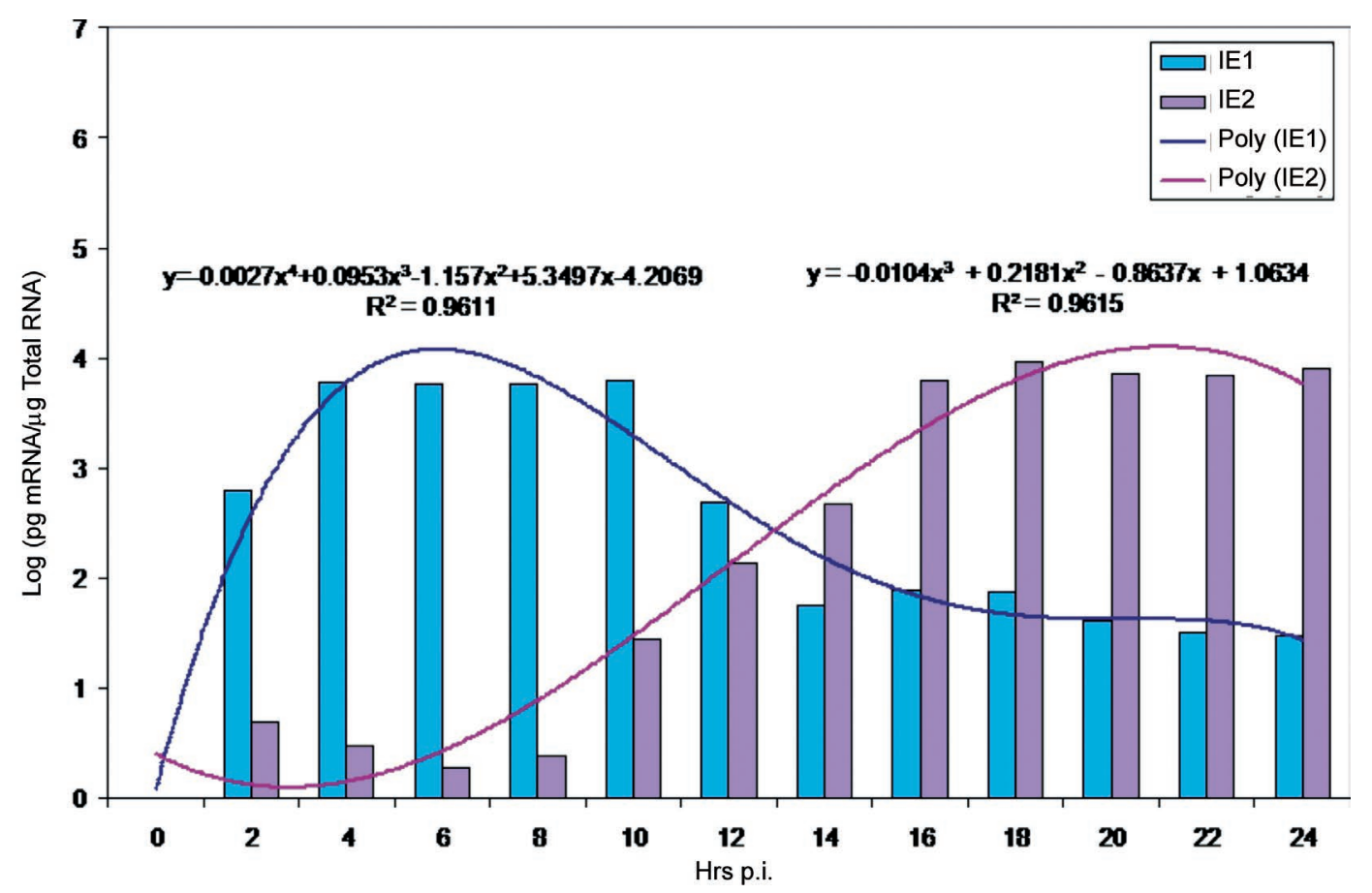

Fig. 5

Kinetic quantification of transcription levels of IE1 and IE2 transcripts in RCMV-infected REF cells The trend of the transcription level of each mRNA was represented by a polynomial graph and created formulation. 
Table 1. Comparison of standard curves of IE1 and IE2 sense RNA oligonucleotides generated by TthPlus and QT systems

\begin{tabular}{|c|c|c|c|c|c|}
\hline \multirow{3}{*}{ No. } & \multirow{3}{*}{ RNA (pg)/assay } & \multicolumn{4}{|c|}{$\begin{array}{c}\text { Threshold cycle, } \mathrm{C}(\mathrm{T}) \\
\text { (Mean } \pm \text { standard error of mean) }\end{array}$} \\
\hline & & TthPlus & & TthPlus & \\
\hline & & IE1 & QT & IE2 & QT \\
\hline 1 & 100 & $15.659 \pm 0.577$ & $23.806 \pm 0.293$ & $16.250 \pm 0.642$ & $24.034 \pm 0.313$ \\
\hline 2 & 10 & $19.005 \pm 0.560$ & $27.512 \pm 0.429$ & $19.269 \pm 0.216$ & $25.855 \pm 0.486$ \\
\hline 3 & 1 & $22.537 \pm 0.555$ & $30.462 \pm 0.289$ & $22.397 \pm 0.159$ & $30.003 \pm 0.434$ \\
\hline 4 & 0.1 & $26.180 \pm 0.626$ & $34.508 \pm 0.121$ & $25.251 \pm 0.256$ & $33.595 \pm 0.627$ \\
\hline 5 & 0.01 & $29.581 \pm 0.275$ & $39.491 \pm 0.153$ & $29.374 \pm 0.552$ & $36.538 \pm 0.418$ \\
\hline 6 & 0.001 & $33.576 \pm 0.146$ & - & $32.338 \pm 0.202$ & - \\
\hline
\end{tabular}

Table 2. Kinetic transcription levels of IE1 and IE2 determined by modified protocol of real-time RT-PCR in RCMV-infected REF cells

\begin{tabular}{cll}
\hline & \multicolumn{2}{c}{$\begin{array}{c}\text { Concentration of mRNA in infected REF per total } \\
\text { cellular RNA (pg/ } \mu \mathrm{g})\end{array}$} \\
Time (hrs p.i.) & \multicolumn{2}{c}{ (Mean \pm standard error of mean) } \\
\cline { 2 - 3 } & \multicolumn{1}{c}{ mRNA IE1 } & mRNA IE2 \\
\hline 0 & $0.00 \pm 0.00$ & $0.00 \pm 0.00$ \\
2 & $616.60 \pm 58.36$ & $4.90 \pm 0.70$ \\
4 & $6025.60 \pm 75.61$ & $2.95 \pm 0.57$ \\
6 & $5754.40 \pm 120.00$ & $1.91 \pm 0.19$ \\
8 & $5888.44 \pm 141.07$ & $2.40 \pm 0.42$ \\
10 & $6180.16 \pm 34.55$ & $27.45 \pm 0.92$ \\
12 & $489.78 \pm 28.18$ & $136.15 \pm 14.54$ \\
14 & $56.23 \pm 6.41$ & $477.95 \pm 5.46$ \\
16 & $77.63 \pm 4.46$ & $6309.57 \pm 102.27$ \\
18 & $75.86 \pm 5.38$ & $9314.62 \pm 85.94$ \\
20 & $41.69 \pm 6.65$ & $7220.00 \pm 68.02$ \\
\hline 22 & $32.36 \pm 3.40$ & $6943.20 \pm 183.58$ \\
24 & $30.20 \pm 2.48$ & $7991.15 \pm 173.87$ \\
\hline
\end{tabular}

For melting curve analysis, the Tm values of the IE1 and IE2 RNA templates included samples generated by using TthPlus system represented $81.0^{\circ} \mathrm{C}$ and $82.0^{\circ} \mathrm{C}$ and by using QT system $74.6^{\circ} \mathrm{C}$ and $76.4^{\circ} \mathrm{C}$, respectively. NTC showed no defined peaks (data not shown).

Kinetic quantification of in vitro transcription levels of IE mRNAs

The concentration (expressed in pg mRNA per $\mu \mathrm{g}$ of total cellular RNA) of the two RCMV mRNAs (IE1 and IE2) present in infected and mock-infected cells at different time points p.i. is depicted in Table 2 and Fig. 5. The histogram analysis showed that the kinetic levels of two mRNAs were particularly different. The mRNA IE1 had an earlier expression kinetic compared to mRNA IE2. The mRNA IE1 level increased steeply in the very early time p.i. The highest mRNA IE1 levels were at 4-10 hrs p.i. forming a plateau. Afterwards, the concentration of mRNA dropped gradually. The kinetic level of mRNA IE2 seemed to be reverse to that of mRNA IE1. From the beginning, there was a slow increase of mRNA IE2 level to the $16 \mathrm{hrs}$ p.i. and this level was maintained till $24 \mathrm{hrs}$ p.i. The kinetic levels of these two mRNAs could be expressed in polynomial equations with $\mathrm{R}^{2}$ values of 0.96 (Fig. 5). Based on these polynomial formulations, IE1 had a concentration peak at $7 \mathrm{hrs}$ p.i., whereas IE2 at $20 \mathrm{hrs}$ p.i.

\section{Discussion}

An accurate quantification of PCR products is extremely problematic due to the differences in PCR efficiency and altered amplification parameters of large and small quantities of starting template. However, with the advent of realtime RT-PCR, it has become possible to measure amplicon production directly during PCR eliminating most of these technical concerns and providing a more reliable estimate of mRNA transcript levels (Serazin-Leroy et al., 1998).

In our study, single-stranded sense RNA oligonucleotides were employed as a standard control for the absolute quantification of mRNA level. The main advantage of the single-stranded sense oligonucleotides is the process of obtaining a standard curve that is significantly simplified, i.e. avoids the time-consuming production and gives an accurate data about concentration and length of the amplicon. The identical length of standard and sample amplicons generates equivalent RT-PCR efficiency as well as homogeneity during melting curve analysis (Bustin, 2000).

The RT step is critical for a sensitive and accurate quantification and the amount of cDNA produced by reverse transcriptase must accurately represent RNA input amounts. Therefore, the dynamic range, sensitivity, and specificity of the enzyme are prime considerations for a successful RT-PCR assay. Protocols using a one-tube/one-enzyme- 
based approach are significantly more convenient than those using two-tube/two enzyme-based protocols (Battaglia et al., 1998). Thermostable Tth DNA polymerase used in the current study exhibits both phases of the reaction (reverse transcription and amplification) in the same reaction tube in the presence of $\mathrm{Mn}^{2+}$ ions (Myers and Gelfand, 1991; Myers et al., 1994). These conditions permit RT reaction to be carried out at the increased temperatures using primers with a significantly higher $\mathrm{Tm}$, while minimizing hands-on time in addition to the risk of contamination and thereby increasing the specificity of the assay (Mulder et al., 1994). On the other hand, the QT system contained two reverse transcriptases, i.e. Omniscript for reverse transcription of RNA amounts bigger than $50 \mathrm{ng}$, and Sensiscript for use with very small amounts of RNA (less than $50 \mathrm{ng}$ ). The enzymes combination claimed to provide highly efficient and sensitive reverse transcription over a wide range of RNA template amounts. However, it was found that different RNA preparations were likely to give different results with the kit especially for low RNA template as conformed to the previous findings (Bustin, 2002). Moreover, it was unlikely to generate a standard curve with correlation of coefficient values as good as using the TthPlus system (0.9889 to 0.9913 vs 0.9975 to 0.9994 ). This piece of information might be due to a different reaction efficiency of the two enzymes. All quantitative methods assumed that RNA targets were reverse-transcribed and subsequently amplified with a similar efficiency in order to gain an accurate quantification (Bustin, 2002). However, the consistency of the reaction efficiency of QT system remained questionable. In general, the employment of TthPlus polymerase in real-time RTPCR using gene-specific primers produced better results in comparison to QT kit in the current study. Furthermore, the TthPlus system is cost-efficient and merits for quantification of a large number of samples.

During optimization of RT-PCR, choosing the highest annealing temperature with no loss of band intensity minimized the problems encountered with strong secondary structures in RNA. These secondary structures were less stable at higher reaction temperatures and particularly associated with very low concentrations of starting RNA. Higher temperatures also permitted an increased specificity and efficiency of primer hybridization and extension by both forward and reverse primers (Raja et al., 2000). The QT kit applied HotStarTaq DNA polymerase, which required heat activation prior to PCR reaction what provided better specificity (QuantiTect SYBR ${ }^{\circledR}$ Green RTPCR Handbook, 2008). RT-PCR assay that used TthPlus polymerase for reverse-transcriptions and PCR reaction using one-enzyme/one-tube system did not have this advantage and the major sources of non-specificity were impeded mostly by the modified protocol affixing an extra fluorescence acquisition step.
An important limitation of SYBR Green is the efficient binding to the non-specific products like primer-dimers as well as to the desired product. This fact interferes with a quantification of the desired PCR product. Its formation can be reduced by careful primer design, optimization of PCR with 'hot start' PCR and amplification under stringent conditions (Harris and Jones, 1997). However, primer-dimers can occur even under optimally determined conditions regardless of the primer design and complementarity. Thus, re-designing primers are not always an acceptable solution as it is sometimes either impossible or impractical. A melting curve analysis differentiated between PCR products such as primer-dimers and the desired product. Primer-dimers exhibited a lower Tm than the desired amplicon as they were considerably shorter (Brownie et al., 1997).

The standard protocol for quantitative RT-PCR utilized 40 cycles of denaturation, annealing and extension, with fluorescence measured at the end of each extension segment. Taking advantage of our knowledge of the Tm of the primer-dimers $\left(75.6^{\circ} \mathrm{C}\right)$ of gene IE1 and the ability to read fluorescence at any point during the cycle, an additional segment was added in order to circumvent primer-dimer interference. After elongation, the temperature was increased to $78^{\circ} \mathrm{C}$, lower than Tm of the desired IE1 product $\left(81.0^{\circ} \mathrm{C}\right)$, but greater than the $\mathrm{Tm}$ of the primer-dimers $\left(75.6^{\circ} \mathrm{C}\right)$. Similarly, a segment of $79^{\circ} \mathrm{C}$ was added to the gene IE2 protocol, where the Tm of desired product was $82^{\circ} \mathrm{C}$. Fluorescence was measured at this point ensuring that only the fluorescence of the desired amplicon was detected, since at this temperature primer-dimers were single-stranded and did not bind SYBR Green.

Quantitative RT-PCR of the positive standard control series using this modified protocol demonstrated virtually complete elimination of the primer-dimer contribution to the total fluorescence. Thus, compared to the unmodified protocol, a much clearer dose response fluorescence profile for the positive control serial dilutions was obtained. The decrease in fluorescence of the positive controls was due to the loss of fluorescence from primer-dimers. Therefore, the results obtained reflected fluorescence from IE1 and IE2 products uncontaminated by primer-dimer fluorescence. In the current study with this modified protocol, a sensitive, specific and reproducible one-tube/one- enzyme real-time RT-PCR was successfully developed.

Yet, PCR is not equally efficient with the two genes, even if the amounts of template are the same. The TthPlus system was more sensitive than QT for detection of IE1 and IE2 genes with higher and comparable amplification efficiencies, respectively. Besides, the TthPlus system generated amplicons with higher Tm than those of QT. The differences of a buffer composition and salt concentration of the two systems influenced the melting point of the products. Consequently, the TthPlus systems produced amplicons 
with a higher stability. All these points greatly supported the employment of TthPlus system for kinetic quantification of in vitro transcription levels of the two mRNAs.

The total RNA contains sub-fractions of ribosomal RNA (80-85\%), transfer RNA (10-15\%) and messenger RNA (1-5\%), which can vary considerably from sample to sample (Pfaffl, 2001). These sub-fractions were assumed to be constant in all RNA samples isolated in different time intervals. The presence of the IE mRNAs in RCMV-infected cells with different concentration throughout the study is due to the superior sensitivity of real-time RT-PCR. As little as a single copy of a particular sequence can be specifically amplified and detected. The two IE mRNAs are transcribed at least up to $24 \mathrm{hrs}$. The kinetic transcription patterns of both IE1 and IE2 mRNAs were distinct from each other. The IE1 is more reflective with its IE property as it was transcribed earlier than IE2. Nevertheless, the level of an mRNA species is affected by its rate of degradation as well as by its rate of synthesis. The lifespan of most eukaryotic mRNA molecules is measured in hours (Dale and Schantz, 2002). It possibly implies the lower stability of IE1 that declined with time. In previous reports, the IE mRNA was transcribed to the highest level in $4.5 \mathrm{hrs}$ tested by PCR in HCMV-infected fibroblasts (Kerry et al., 1995). Similar to their counterparts from HCMV (Stenberg et al., 1989; Rawlinson and Barrell, 1993) and MCMV (Keil et al., 1987; Messerle et al., 1992), both IE1 and IE2 of RCMV, strain Maastricht were transcribed during IE phase of infection. However, late-phase-specific transcripts from MIE locus had previously also been identified for HCMV and RCMV, strain Maastricht. During the late phase (up to 48 hrs p.i.) of infection with RCMV, strain Maastricht, IE2 but not IE1 was transcribed, while in the late phase of HCMV infection both IE1 $1_{491 \text { aa }}$ and IE2 ${ }_{579 a a}$ transcripts were produced (Rawlinson and Barrell, 1993). In addition, the IE2A mRNA was almost exclusively produced at the late time of RCMV infection (Beisser et al., 1998). Hence, the transcription patterns of mRNAs IE1 and IE2 of RCMV conformed to those mentioned in the previous findings.

On the other hand, a kinetic expression of IE proteins synthesized in Towne HCMV-infected human blastoma (IMR-32) and human embryonic lung (HEL) cells by Western blot analysis was conducted by Sadanari et al. (2000). They found that IE1 was detected initially at $3 \mathrm{hrs}$ p.i. and its production increased till $12 \mathrm{hrs}$ p.i., then declined gradually. IE2 was first detected at $6 \mathrm{hrs}$ p.i. and its production increased until 72 hrs p.i. In IMR-32 cells, IE1 and IE2 appeared at 6 and 12 hrs p.i., respectively, and their expression levels increased gradually until $72 \mathrm{hrs}$ p.i. The steady-state levels of IE1 after $24 \mathrm{hrs}$ p.i. exceeded those found in HEL cells (Sadanari et al., 2000). These results implied that there were differences in the regulation of protein synthesis in the permissive cells. These different regulatory events may be crucial in determination of the relative levels of the IE pro- teins, which are likely to influence the course of subsequent viral gene expression (Kerry et al., 1995). The findings in the current study conformed to the previous reports in both transcription and expression levels especially with the results of RCMV, strain Maastricht.

One of the limitations of this study is the 24 hrs cut-off period, what makes the observations beyond that time inaccessible. We believe that both IE1 and IE2 mRNAs have persisted until $48 \mathrm{hrs}$ p.i., what corresponds with the results of Beisser et al. (1998). This is due to the asynchronous development of RCMV in vitro, which was mentioned previously in Loh et al. (2003) involving the virus binding, penetration, regulation of transcription and translation, DNA replication, virion assembly, maturation, and egress. Nevertheless, this kinetic transcription study warrants further investigations on the alternative splicing phenomenon of the two IE mRNAs. This work will be conducted by designing the primers flanking at the spliced junctions of exon 3/exon 4 (IE1) and exon 3/exon 5 (IE2) to assess the levels of spliced IE transcripts using the newly developed RT-PCR assay.

In conclusion, the in-house real-time RT-PCR assay was successfully developed for quantification of the IE1 and IE2 mRNAs levels with findings conforming to the previous transcription and expression studies with HCMV (Stenberg et al., 1989; Rawlinson and Barrell, 1993), MCMV (Keil et al., 1987; Messerle et al., 1992), and RCMV, strain Maastricht (Beisser et al., 1998). Since RCMV is one of the animal models for studying CMV infection and disease in human, this assay appears as the suitable alternative for rapid diagnosis and monitoring of the acute CMV infection by detection of IE mRNAs that directly reflect the biological activity of the infecting virus.

\section{References}

Battaglia M, Pedrazzoli P, Palermo B, Lanza A, Bertolini F, Gibelli N, da Prada GA, Zambelli A, Perotti C, Robustelli Della Cuna G (1998): Epithelial tumour cell detection and the unsolved problems of nested RT-PCR: a new sensitive one step method without false positive results. Bone Marrow Transpl. 22, 693-698. doi:10.1038/sj.bmt.1701405

Beisser PS, Kaptein SJF, Beuken E, Bruggeman CA, Vink C (1998): The Maastricht strain and English strain of rat cytomegalovirus represent different Betaherpesvirus species rather than strains. Virology 246, 341-351. doi:10.1006/viro.1998.9196

Brownie J, Shawcross S, Theaker J, Whitcombe D, Ferrie R, Newton C, Little S (1997): The elimination of primer-dimer accumulation in PCR. Nuc. Acids Res. 25, 3235-3241. doi:10.1093/nar/25.16.3235

Bustin SA (2000): Absolute quantification of mRNA using realtime reverse transcription polymerase chain reaction assays. J. Mol. Endocrinol. 25, 169-193. doi:10.1677/ ime. 0.0250169 
Bustin SA (2002): Quantification of mRNA using real-time reverse transcription PCR (RT-PCR): trends and problems. J. Mol. Endocrinol. 29, 23-39. doi:10.1677/jme.0.0290023

Cohen CD, Frach K, Schlondorff D, Kretzler M (2002): Quantitative gene expression analysis in renal biopsies: a novel protocol for a high-throughput multicenter application. Kidney Int. 61, 133-140. doi:10.1046/j.1523-1755.2002.00113.x

Dale JW, Schantz M von (2002): From Genes to Genomes: Concepts and Applications of DNA Technology. London: John Wiley and Sons. doi:10.1002/0470856912 S (149 citations) $\quad \mathrm{S}(24$ citations)

Harris S, Jones DB (1997): Optimization of the polymerase chain reaction. Brit. J. Biomed. Sci. 54, 166-173.

Keil GM, Ebelling-Keil A, Koszinowski UH (1987): Immediateearly genes of murine cytomegalovirus: location, transcripts, and translation products. J. Virol. 61, 526-533.

Kerry JA, Sehgal A, Barlow SW, Cavanaugh VJ (1995): Isolation and characterization of a low-abundance splice variant from the human cytomegalovirus major immediate-early gene region. J. Virol. 69, 3868-3872.

Liu J, Feldman P, Chung TD (2002): Real-time monitoring in vitro transcription using molecular beacons. Anal. Biochem. 300, 40-45. doi:10.1006/abio.2001.5446

Loh HS, Mohd-Azmi ML, Lai KY, Sheikh-Omar AR, Zamri-Saad M (2003): Characterization of a novel rat cytomegalovirus (RCMV) infecting placenta-uterus of Rattus rattus diardii. Arch. Virol. 148, 2353-2367. doi:10.1007/s00705-003-0173-y

Loh HS, Mohd-Azmi ML, Sheikh-Omar AR, Kiew LJ (2006): Pathogenicity and vertical transmission of a transplacental rat cytomegalovirus. J. Virol. 3, 42. doi:10.1186/1743$\underline{422 X-3-42}$

Loh HS, Mohd-Azmi ML, Sheikh-Omar AR, Zamri-Saad M and Tam YJ (2007a): Pathogenesis and antibody response to a cytomegalovirus infection in newborn rats. Acta Virol. 51, 27-33.

Loh HS, Mohd-Azmi ML, Sheikh-Omar AR, Zamri-Saad M, Zeenathul NA (2007b): Molecular characterization and identification of the immediate-early (IE) genes of rat cytomegalovirus (RCMV). J. Vet. M'sia. 19, 21-32.

Messerle M, Buhler B, Keil GM, Koszinowski UH (1992): Structural organisation, expression, and functional characterisation of the murine cytomegalovirus immediate-early gene 3. J. Virol. 66, 27-36.

Mocarski ES (1996): Cytomegalovirus and their replication. In Field BN, DM Knipe, PM Howley (Eds): Virology. Philadelphia: Lippincott-Raven, pp. 2447-2492.
Mulder J, McKinney N, Christopherson C, Sninsky J, Greenfield L, Kwok S (1994): Rapid and simple PCR assay for quantitation of human immunodeficiency virus type I RNA in plasma: Application of acute retroviral infection. J. Clin. Microbiol. 32, 292-300.

Myers TW, Gelfand DH (1991): Reverse transcription and DNA amplification by a Thermus thermophilus DNA polymerase. Biochem. 30, 7661-7666. doi:10.1021/bi00245a001

Myers TW, Sigua CL, Gelfand DH (1994): High temperature reverse transcription and PCR with a Thermus thermophilus DNA polymerase. Nuc. Acids Symp. Ser. 30, 87.

Pfaffl MW (2001): Development and validation of an externally standardized quantitative Insulin like growth factor-1 (IGF-1) RT-PCR using LightCycler SYBR Green I technology. In Meuer S, C Wittwer, K Nakagawara (Eds): Rapid Cycle Real-time PCR, Methods and Applications. Heidelberg, Springer Press, pp. 281-191.

Raja S, Luketich JD, Kelly LA, Ruff DW, Godfrey TE (2000): Increased sensitivity of one-tube, quantitative RT-PCR. Biotechniques 29, 702.

Rawlinson WD, Barrell BG (1993): Spliced transcripts of human cytomegalovirus. J. Virol. 67, 5502-5513.

Ririe KM, Rasmussen RP, Wittwer CT (1997): Product differentiation by analysis of DNA melting curves during the polymerase chain reaction. Anal. Biochem. 245, 154-160. doi:10.1006/abio.1996.9916

Sadanari H, Yamada R, Yamagoshi T, Ohnish K, Matsubara K, Fukuda S, Tanaka J (2000): The major immediate-early genes of human cytomegalovirus induce two novel proteins with molecular weights of 91 and 102 kilodaltons. Arch. Virol. 145, 1257-1266. doi:10.1007/ $\underline{\mathrm{s} 007050070125}$

Serazin-Leroy V, Denis-Henriot D, Morot M, de Mazancourt P, Giudicelli Y (1998): Semi-quantitative RT-PCR for comparison of mRNAs in cells with different amounts of housekeeping gene transcripts. Mol. Cell Probes 12, 283-291. doi:10.1006/mcpr.1998.0182

Stenberg RM, Depto AS, Fortney J, Nelson JA (1989): Regulated expression of early and late RNA and protein from the human cytomegalovirus immediate-early gene region. J. Virol. 63, 2699-2708.

Wall SJ, Edwards DR (2002): Quantitative reverse transcriptionpolymerase chain reaction (RT-PCR): a comparison of primer-dropping, competitive, and real-time RTPCRs. Anal. Biochem. 300, 269-273. doi:10.1006/ $\underline{\text { abio. } 2001.5458}$ 